\title{
Mechanical and Durability Characteristics of Roller Compacted Geopolymer Concrete Using Reclaimed Asphalt Pavement
}

\author{
Sk Syfur Rahman \\ syfur04016@gmail.com \\ University of Louisiana at Lafayette, Lafayette, Louisiana, USA \\ Mohammad Jamal Khattak \\ khattak@louisiana.edu \\ University of Louisiana at Lafayette, Lafayette, Louisiana, USA
}

\begin{abstract}
Every year a large quantity of reclaimed asphalt pavement (RAP) is generated in the USA. Utilization of RAP can solve the storage problem, prevent environmental pollution and reduce construction costs. This study focuses on the strength and durability characteristics of RAP mixtures by introducing the concept of roller-compacted fly ash-based geopolymer concrete (RCGPC). Several selected RCGPC mixtures were investigated to evaluate the effect of mixture variables, including sodium hydroxide $(\mathrm{NaOH})$ molarity, sodium silicate $\left(\mathrm{Na}_{2} \mathrm{SiO}_{3}\right)$ to sodium hydroxide $(\mathrm{NaOH})$ ratio on the strength, modulus and durability characteristics of the mixtures. The effects of different curing temperature and curing duration on compressive strength were also studied. It was found that the mixtures with $\mathrm{Na}_{2} \mathrm{SiO}_{3} / \mathrm{NaOH}$ ratio of 1 yielded about $12 \%$ higher compressive strength than the ratio of 0 . Further, the mixtures using $10 \mathrm{M} \mathrm{NaOH}$ and alkali ratio of 1 produced about $25 \%$ higher compressive strength than $8 \mathrm{M} \mathrm{NaOH}$ which produced about $17 \mathrm{MPa}$. Similar results were obtained for elastic modulus and split tensile strength of the mixtures. Freeze-thaw durability tests also revealed acceptable results for the RCGPC mixtures. Formation of new geopolymeric compounds and chemical bonds in the newly formed novel RCGPC mixtures were also discovered using XRD analysis. The comparison of mechanical and durability testing further showed that RCGPC performed better than the roller-compacted cement concrete (RCC) using RAP. Based on the results and analysis the developed RCGPC using RAP could be used as a cost-effective solution for the construction of pavement structures.
\end{abstract}

Keywords: Roller compacted concrete; Geopolymer concrete; Reclaimed asphalt pavement; Pavement; Fly ash

\section{INTRODUCTION}

Every year vast quantities of construction and demolition (C\&D) wastes are generated in the United States (EPA, 2019). Reclaimed asphalt pavement (RAP) is one of the main components of such C\&D wastes. The use of RAP can solve storage problems and environmental pollution while at the same time it can reduce construction costs (EPA, 2019; Davorin, 2008 \& Ryszard, 2016). However due to the low strength and durability properties of RAP, its usage as a construction material is limited to landfill, low strength base or subbase and replacement of few percentages of natural aggregates in hot mix asphalt (HMA) and conventional Portland cement concrete (Copeland, 2011; Chesner, 
2019; Hansen, 2014; Hoyos, 2011; Arulrajah, 2013; Puppala, 2011; Hajj, 2010; Maher, 1997; Ramzi, 1999; Huang, 2006 \& Huang, 2005). Although Ordinary Portland Cement $(\mathrm{OPC})$ is being used as a popular binder for a long time, its increasing production generates an enormous amount of $\mathrm{CO}_{2}$ in the atmosphere, which is also raising environmental concerns (Malhotra, 2010; Naik, 2015 \& Salloum, 2007). Geopolymer technology can be a possible alternative to address this issue.

Geo-polymer technology has become a promising technology that provides a mature and cost-effective solution to many problems. Geo-polymeric materials represent an opportunity to simultaneously improve both environmental and engineering performance compared to traditional technologies. Geo-polymer-based materials are environmentally friendly and need only moderate energy to produce. The development of Geopolymer technology could contribute to reducing $\mathrm{CO}_{2}$ emissions by about $80 \%$ as compared to that of ordinary Portland cement with almost no economic sacrifices, while at the same time converting a potentially hazardous industrial waste by-product (fly ash) to a value-added construction material (Davidovits, 2008). The use of RAP in geopolymer can be more beneficial because in this way both waste products RAP and fly ash will be utilized resulting in not only saving the cost but also reducing the amount of $\mathrm{CO}_{2}$ emission. Recently, RAP is being used in geopolymer concrete by researchers in many ways. They investigated different gradations of RAP, different mix variables like fly ash to alkali activator ratio, the different molar concentration of alkali activator (Delwar, 1997; Hossiney, 2008; Avirneni, 2016 \& Horpibulsuk, 2016). However, in none of the above-mentioned studies, the reported improvements in strength and durability were significantly high enough to use RAP alone as a full replacement of natural aggregates.

In this study, the concept of roller-compacted geopolymer concrete (RCGPC) was introduced to improve the strength and durability characteristics of concrete containing RAP as aggregates. Mechanical and durability properties, as well as the morphology of prepared geopolymer mixtures, were investigated and compared with roller-compacted cement concrete (RCC) with RAP.

\section{MATERIALS}

The chemical composition of Class F fly ash (FA) used in this study is shown in Table 1. This low calcium FA contains $14.82 \%$ aluminum oxides and $36.40 \%$ silicon dioxide. RAP was secured from a local HMA recycling plant. Chemical analysis of RAP has also been tabulated in Table 1. Sodium hydroxide $(\mathrm{NaOH})$ solutions of 8 and 10 molar concentrations were prepared in the laboratory. On the other hand, a ready-made sodium silicate $\left(\mathrm{Na}_{2} \mathrm{SiO}_{3}\right)$ solution was also used as part of the alkali activator. Portland cement Type-II was used for RAP-based RCC specimens.

Table 1: Chemical composition of FA and RAP

\begin{tabular}{|c|c|c|}
\hline Element (\%) & FA & RAP \\
\hline $\mathrm{Si}$ & 36.40 & 48.37 \\
\hline $\mathrm{Al}$ & 14.82 & 16.63 \\
\hline $\mathrm{Fe}$ & 12.17 & 15.33 \\
\hline $\mathrm{Ca}$ & 13.87 & 13.30 \\
\hline $\mathrm{Mg}$ & 0.79 & - \\
\hline $\mathrm{S}$ & 0.57 & - \\
\hline $\mathrm{K}$ & 1.59 & 2.38 \\
\hline
\end{tabular}


A suitable mix-design was developed based on the literature search, which consisted of RAP gradation (Figure 1) recommended by American Concrete Pavement Association (ACPA), $15 \%$ fly ash content, 8 and 10 molar concentration of $\mathrm{NaOH}$, and $\mathrm{Na}_{2} \mathrm{SiO}_{3}$ to $\mathrm{NaOH}$ ratio of 0 and 1 by mass. Both accelerated oven and ambient temperature curing methods were adopted to evaluate the mechanical properties of the mixtures.

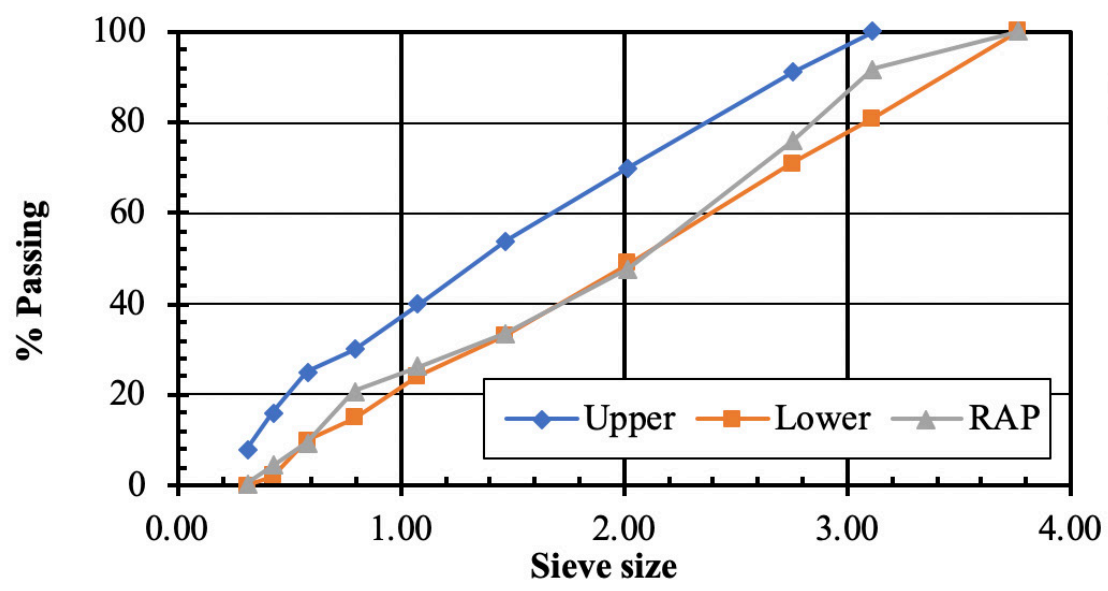

Figure 1: RAP gradation with ACPA recommended upper and lower limits for RCC

\section{METHODS}

\subsection{Maximum dry density (MDD) and optimum alkali content (OMC)}

The maximum dry density (MDD) of the mixtures was determined using the modified proctor test (ASTM, D1557). The mixtures were compacted in a cylindrical mold with a dimension of $142.4 \mathrm{~mm}$ diameter and $116.4 \mathrm{~mm}$ height. The compaction was done in 5 layers, by applying 25 blows per layer, using a $2.5 \mathrm{~kg}$ hammer. The height of the fall of the hammer was $45.7 \mathrm{~cm}$. Geopolymer mixtures were prepared using 4 different alkali contents, which were then compacted to determine the dry density of those. However, for RCC mixtures 4 different moisture contents were used. MDD and OMC were determined by plotting a dry density versus alkali or moisture content graphs.

\subsection{Experimental design parameters}

To find out the optimum oven curing time at $60^{\circ} \mathrm{C}$ temperature, 3 oven curing periods (24, 48 and $72 \mathrm{hr}$ ) were used. To determine the optimum alkali content (OMC) of the mixtures, using modified proctor test, 4 different alkali and moisture contents ranging from $5 \%$ to $10 \%$ for RCGPC and $5 \%$ to $9 \%$ for RCC, respectively, were used. The effect of molarity on compressive and split tensile strengths of RCGPC were evaluated for 8 and 10 molar $\mathrm{NaOH}$ concentration. Similarly, the impact of $\mathrm{Na}_{2} \mathrm{SiO}_{3}$ to $\mathrm{NaOH}$ ratio on strengths of RCGPC was evaluated using two different $\mathrm{Na}_{2} \mathrm{SiO}_{3}$ to $\mathrm{NaOH}$ ratio of 0 and 1. For ambient temperature curing 7, 14, 28 and 56 days were also investigated. Loading frequency for dynamic modulus testing was varied as $0.5,1,5,10$, and $25 \mathrm{~Hz}$. For durability and morphology analysis the RAP-RCGPC mixture produced from $8 \mathrm{M}$ $\mathrm{NaOH}, \mathrm{Na}_{2} \mathrm{SiO}_{3}$ to $\mathrm{NaOH}$ ratio of 1 was used. 


\subsection{Unconfined compressive strength test}

An unconfined compressive strength (UCS) test was performed according to ASTM C39 using Material Testing System (MTS). The compressive load was applied at a continuous rate of $0.51 \mathrm{~mm} / \mathrm{min}$ until complete failure of the specimen was visible. The data acquisition rate for load and deformation was set as 0.1 per second. The maximum compressive stress at failure was defined as UCS and the slope of the linear portion of the stress-strain curve was termed as elastic modulus (E) of the mixtures.

\subsection{Split tensile test}

Split tensile strength test was performed similarly to ASTM C496 using Material Testing System (MTS). The load was applied along the diametral axis of the specimen at a continuous rate of $0.51 \mathrm{~mm} / \mathrm{min}$ until complete failure was observed. Real-time data acquisition at a rate of 0.1 per second was set. This test was used to evaluate split tensile strength $(\mathrm{T})$ of the mixtures.

\subsection{Durability test (Resistance to freeze-thawing)}

Resistance to freeze-thawing was performed in accordance with ASTM C666 standard procedure. Cylindrical specimens with $100 \mathrm{~mm}$ diameter and $200 \mathrm{~mm}$ height were subjected to consecutive freeze and thawing cycles. The temperature was increased from $-12^{\circ} \mathrm{C}$ to $12^{\circ} \mathrm{C}$ within 2 to $5 \mathrm{hr}$ and then decreased from $12^{\circ} \mathrm{C}$ to $-12^{\circ} \mathrm{C}$ in 2 to $5 \mathrm{hr}$. The length change of the specimens was measured in every 36 cycles. Each specimen was to be subjected to 300 cycles or $1 \%$ length change.

\subsection{X-ray diffraction (XRD)}

XRD analysis was carried out using the MiniFlex600 XRD machine. The range of diffraction angle, $2 \theta$ used in this analysis was varied from 5 to $55^{\circ}$. This test facilitated the identification of chemical compounds formed during geopolymerization.

\section{RESULTS AND DISCUSSIONS}

\subsection{Optimum moisture content}

Figure 2 shows the change in dry density with the increase in alkali content for RCGPC and water content for RCC mixtures. The alkali content was varied from 5 to $10 \%$ for RCGPC and water content 5 to $9 \%$ for RCC mixtures. İt was observed from the figure that, as the alkali content increased, the dry density also increased and finally reached a maximum value of 6-7\% and dropped afterward. Optimum alkali content and maximum dry density (MDD) were found to be $6.3 \%$ to $7.2 \%$ and 2056 to $2070 \mathrm{~kg} /$ $\mathrm{m}^{3}$ for RCGPC mixtures, respectively. The RCC mixture using OPC exhibited optimum moisture content (OMC) and MDD of $7 \%$ and $2080 \mathrm{~kg} / \mathrm{m}^{3}$, respectively. 


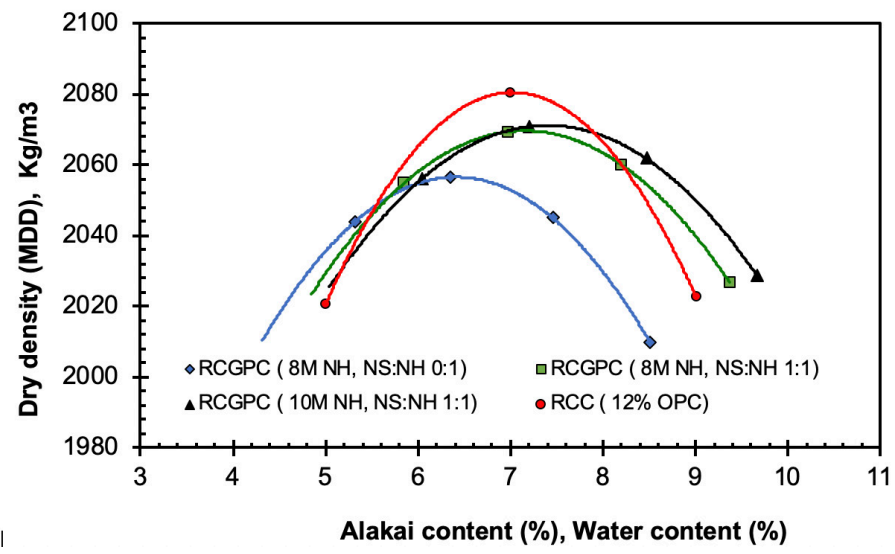

Figure 2: Effect of alkali and water content on the dry density of RAP-RCGPC and RAPRCC mixtures, respectively

\subsection{Effect of curing time}

Figure 3 illustrates the effect of oven curing time on the compressive strength development of the RCGPC mixture at $60^{\circ} \mathrm{C}$. It was observed from the figure that, as the oven curing time increased, the average UCS also increased until 48 hours of curing, after which no significant increase in UCS was observed. Hence, 48 hours of oven curing at $60^{\circ} \mathrm{C}$ was considered to be the optimum accelerated oven curing time for RAP-RCGPC mixtures to evaluate the mechanical and durability characteristics of the mixtures.

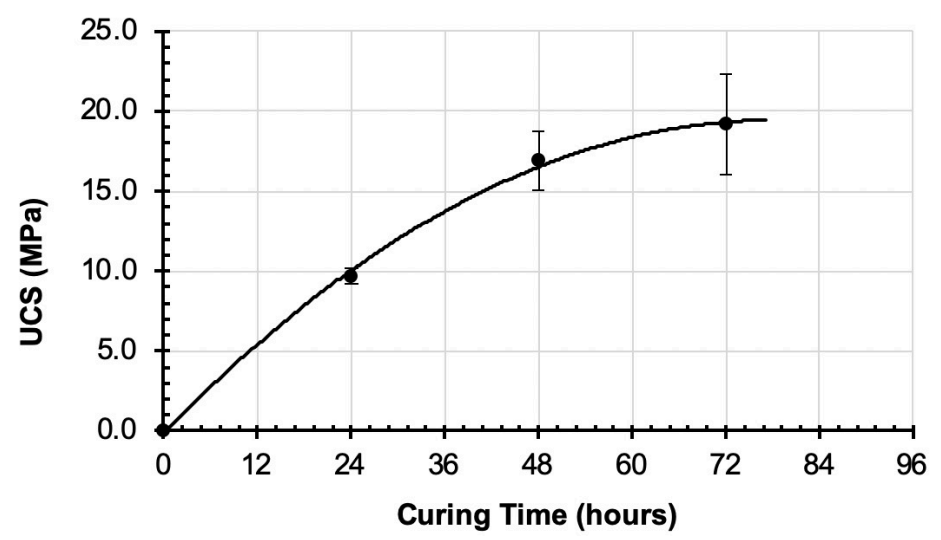

Figure 3: Effect of oven curing time on the UCS of RAP-RCGPC mixtures.

\subsection{Effect of $\mathrm{NaOH}$ molarity and $\mathrm{Na}_{2} \mathrm{SiO}_{3}$ to $\mathrm{NaOH}$ ratio on UCS}

Figure 4 shows the effect of $\mathrm{NaOH}$ molarity on the UCS and E of RAP-RCGPC mixtures. It was observed from the figure that, as the molarity of $\mathrm{NaOH}$ increased from 8 to 10 molar, the UCS also increased by about $25 \%$. However, the increase in the average $\mathrm{E}$ value was only $5 \%$. The heat condition remaining the same, the strength development in geopolymer is mostly dependent on the geo-polymerization reaction between precursor and alkali activator. With the increase of $\mathrm{NaOH}$ molarity, increasing alkali solids in the activator solution enhanced the geo-polymerization reaction and 
process, which increased the strength and modulus of the final mixture.

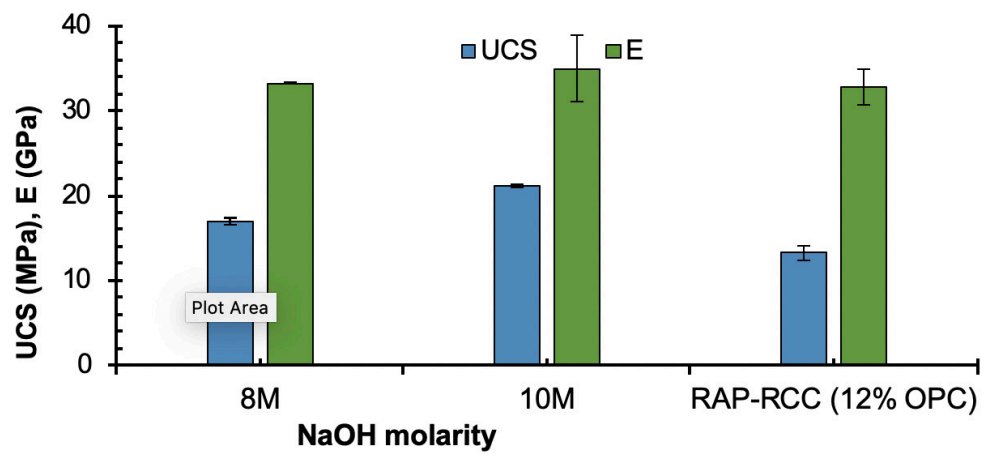

Figure 4: Effect of $\mathrm{NaOH}$ molarity on the UCS of RAP-RCGPC mixtures

UCS and E of RAP-RCC using $12 \%$ ordinary portland cement (OPC) were found to be about 13.24 MPa and 32.82 GPa. UCS of 8M and 10M RAP-RCGPC were about $28 \%$ and $60 \%$ more than UCS of RAP-RCC, however, RAP-RCC had shown similar E value as RAP-RCGPC.

Figure 5 displays the effect of $\mathrm{Na}_{2} \mathrm{SiO}_{3}$ to $\mathrm{NaOH}$ ratio on the UCS and $\mathrm{E}$ of RAPRCGPC mixtures. It can be seen from the figure that, as this ratio increases from 0 to 1 , the UCS increased by about $12 \%$. The $\mathrm{E}$ value also followed a similar trend. The reason behind the high strength and modulus at an equal mass ratio of $\mathrm{Na}_{2} \mathrm{SiO}_{3}: \mathrm{NaOH}$ was the dissolution process of alumina and silica tends to be high, which also accelerates the strength development. As a result, the formed bonds were strong enough to enhance initial microcrack resistance (Morsy, 2014). UCS of RAP-RCGPC using $8 \mathrm{M} \mathrm{NaOH}$ and $\mathrm{Na}_{2} \mathrm{SiO}_{3}: \mathrm{NaOH}$ ratio as 0 and 1 are about $14 \%$ and $28 \%$ more than UCS of RAP-RCC, respectively. However, RAP-RCC has a similar elastic modulus value as that of RAPRCGPC.

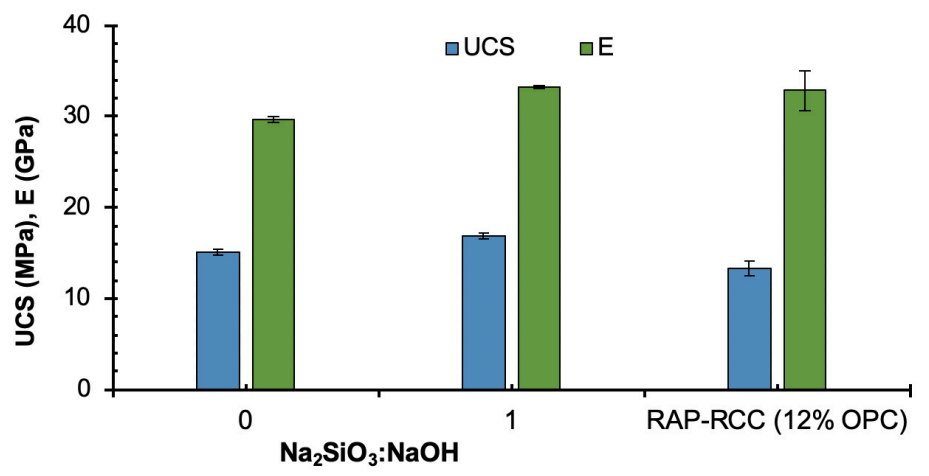

Figure 5: Effect of $\mathrm{Na}_{2} \mathrm{SiO}_{3}$ to $\mathrm{NaOH}$ ratio on the UCS of RAP-RCGPC mixtures

\subsection{Effect of ambient temperature curing}

Effect of ambient temperature curing period of 7, 14, 28 and 56 days on the strength development of RAP-RCGPC was also investigated. Figure 6 demonstrates the effect of ambient temperature curing days on the UCS and E of RAP-RCGPC mixtures. It can be 
seen from the test results that, with the increase in curing days the UCS and E increased. Most of the strength development was observed in the first 7 days $(9.8 \mathrm{MPa})$ of curing, which was around $50 \%$ of the 56 days $(19.76 \mathrm{MPa})$ strength.

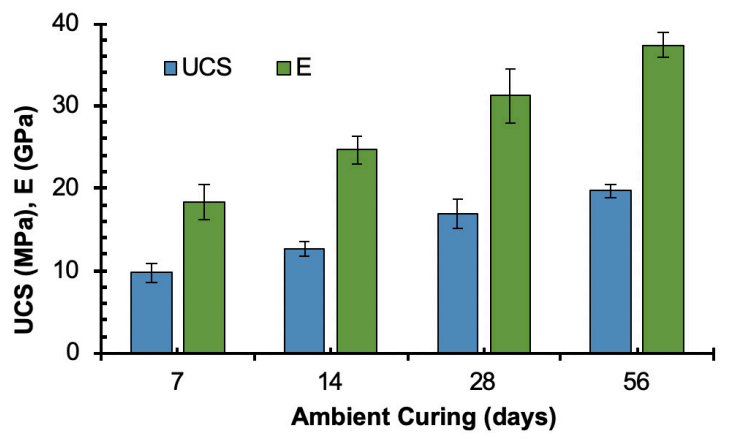

Figure 6: Effect of ambient temperature curing days on the UCS of E RAP-RCGPC mixtures

It was also estimated that 28 days of ambient temperature curing strength was the same as that of the UCS $(16.90 \mathrm{MPa})$ at $60^{\circ} \mathrm{C}$ accelerated oven curing. It should be noted that the average day and night-time specimen temperatures were recorded around $34.4 \pm$ $5.3^{\circ} \mathrm{C}$ and $28.8 \pm 2.1^{\circ} \mathrm{C}$, respectively through these curing days.

\subsection{Dynamic modulus $\left(\mathrm{E}^{*}\right)$}

Cylindrical specimen oven cured at $60^{\circ} \mathrm{C}$ were subjected to sinusoidal loading for a range of loading frequencies $(0.5,1,5,10$ and $25 \mathrm{~Hz})$. İt was observed from Figure 7 that, the $\mathrm{E}^{*}$ increased by $29 \%$ when the loading frequency increased up to $5 \mathrm{~Hz}$, afterward there was no significate change at $10 \mathrm{~Hz}$ and then showed a decrease of about $14 \%$ at $25 \mathrm{~Hz}$. This indicates that such mixtures exhibited some viscoelastic behavior from $0.5 \mathrm{~Hz}$ to $10 \mathrm{~Hz}$ at $25^{\circ} \mathrm{C}$ which may be due to the presence of asphalt coating around the RAP particles. The range of $\mathrm{E}^{*}$ was $15 \mathrm{GPa}$ to $21 \mathrm{GPa}$, which was significantly lower than the E value ( $33 \mathrm{GPa}$ ) of the same mixture.

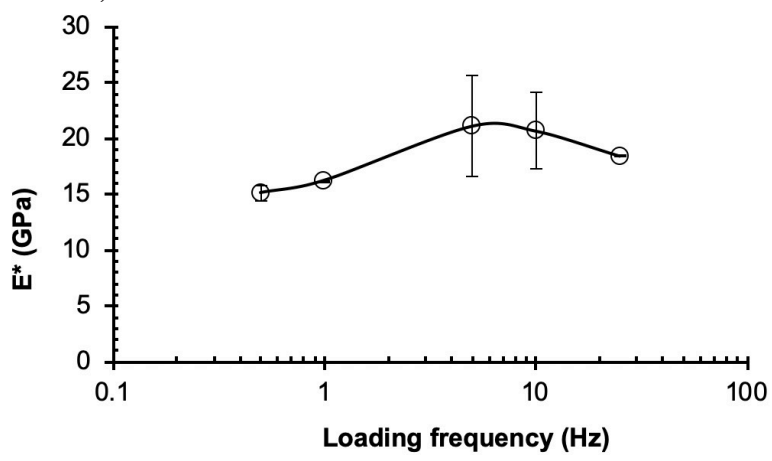

Figure 7: Dynamic modulus of RCGPC mixtures for different loading frequency

\subsection{Split-tensile strength}

The following Figure $8(a, b)$ illustrates the effect of $\mathrm{NaOH}$ molarity and $\mathrm{Na}_{2} \mathrm{SiO}_{3}$ to $\mathrm{NaOH}$ ratio on the split tensile strength of RCGPC mixtures. The data in the figure 
depicts that as the $\mathrm{NaOH}$ molarity increased from 8 to 10 , split tensile strength increased about $10 \%$, however when the $\mathrm{Na}_{2} \mathrm{SiO}_{3}$ to $\mathrm{NaOH}$ ratio increased from 0 to 1 with $8 \mathrm{M}$ $\mathrm{NaOH}$ the there was no significant change in the split tensile strength.
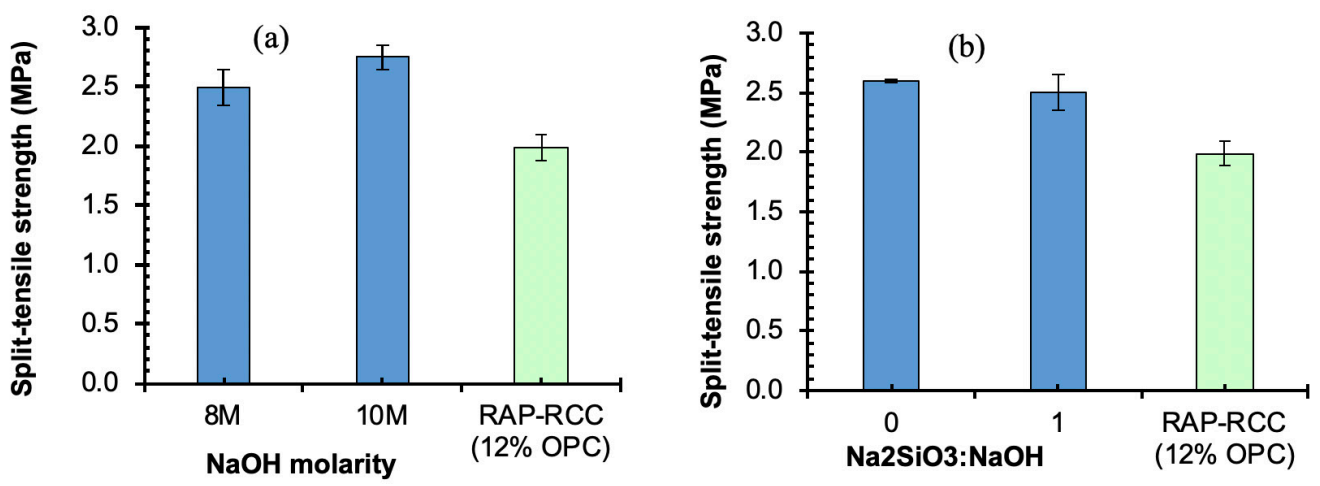

Figure 8. Effect of (a) $\mathrm{NaOH}$ molarity (b) $\mathrm{Na}_{2} \mathrm{SiO}_{3}: \mathrm{NaOH}$ on the split tensile strength of RAP-RCGPC mixtures

RAP-RCC using $12 \%$ OPC exhibited about $2 \mathrm{MPa}$ of split tensile strength which is about $20 \%$ and $28 \%$ lower than RAP-RCGPC mixture with 8 and $10 \mathrm{NaOH}$ respectively. These results indicated a stronger bond between RAP and geopolymer binders in RCGPC than the cement bond in RCC.

\subsection{Durability (freeze-thawing)}

The freeze-thawing durability test was performed on RAP-RCGPC specimens. The specimens had been subjected to 300 cycles of freeze-thawing. Length change was recorded every 36 cycles. Dynamic modulus was determined at the end of the 300 cycles. It was found that the average length change and retained dynamic modulus were about $0.4 \%$ (criteria: $<1 \%$ ) and $81.14 \%$ (criteria: $>60 \%$ ) respectively. So RAP-RCGPC mixtures were considered to be passed in the freeze-thawing durability test.

\subsection{X-ray diffraction}

Figure 9 illustrates the XRD analysis of the RAP-RCGPC mixture. It was observed from the analysis that quartz, mullite, albite and calcium compound present in the fly ash and RAP were chemically acted by alkali activator $\left(\mathrm{Na}_{2} \mathrm{SiO}_{3}\right.$ and $\left.\mathrm{NaOH}\right)$ solution and formed different geopolymer compounds (aluminosilicate), such as Nepheline $\left(\mathrm{NaAlSiO}_{4}\right)$ and Anorthoclase $\left((\mathrm{Na}, \mathrm{K}) \mathrm{AlSi}_{3} \mathrm{O}_{8}\right)$. Some unreacted crystalline quartz and mullite were also visible in the XRD graph. 


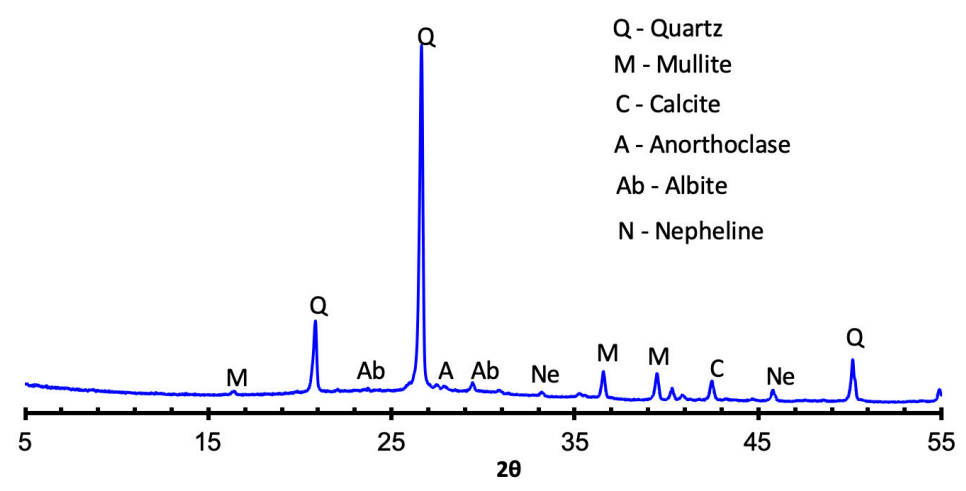

Figure 9: $\mathrm{XRD}$ of $8 \mathrm{M} \mathrm{NaOH}$ with $1: 1 \mathrm{Na}_{2} \mathrm{SiO}_{3}$ cured at $60^{\circ} \mathrm{C}$

\section{CONCLUSION}

This study focused on the investigation of the mechanical, durability, and morphology characteristics of the newly synthesized RAP-RCGPC mixtures using appropriate testing methods. Based on the laboratory test results, the following conclusions were drawn:

1. Compressive strength and elastic modulus increased with the increase in oven curing time at $60^{\circ} \mathrm{C}$ temperature. Accelerated oven curing time of $48 \mathrm{hr}$ at $60^{\circ} \mathrm{C}$ was considered sufficient to achieve the maximum compressive strength of RAPRCGPC mixtures.

2. Compressive strength and elastic modulus of RAP- RCGPC mixtures increased with the increase in ambient curing period. Almost $100 \%$ of maximum strength $\left(60^{\circ} \mathrm{C}\right.$ for $48 \mathrm{hr}$ of oven curing) was achieved in 28 days of ambient curing period.

3. It was found that dynamic modulus increased with the increase in loading frequency up to $5 \mathrm{~Hz}$ and after that frequency increment did not affect the dynamic modulus significantly. In short, RAP- RCGPC mixture exhibited some viscoelastic behavior at $25^{\circ} \mathrm{C}$ at 1 loading frequency ranging from $0.5 \mathrm{~Hz}$ to $10 \mathrm{~Hz}$.

4. The split tensile strength of the RAP-RCGPC mixture increased by about $10 \%$ when the molarity increased from 8 to 10 . However, similar split tensile strength was observed for mixtures containing $8 \mathrm{M} \mathrm{NaOH}$ with and without $\mathrm{Na}_{2} \mathrm{SiO}_{3}$.

5. RAP-RCGPC had exhibited up to $60 \%$ higher UCS and $28 \%$ higher split tensile strength than that of RAP-RCC mixtures using OPC.

6. The XRD test result showed the formation of geopolymer compounds indicating the occurrence of polymerization reaction in RAP-RCGPC mixtures.

Based on the mechanical, durability and morphology analysis, the RAP-RCGPC could be termed as moderate to high strength geopolymer concrete. These mixtures could be used in low volume roads and parking lots as a full-depth pavement or as a strong base with the combination of a hot mix asphalt layer on the top. In this study, the tensile property of the material was evaluated using split tensile testing, however flexural beam testing of such material is recommended to evaluate the modulus of rapture which is an important parameter for pavement design. 


\section{ACKNOWLEDGMENTS}

The authors wish to express sincere thanks to the University of Louisiana at Lafayette for providing financial support and facility for the research. A special thanks are also extended to Mr. Mark LeBlanc for assisting in experimentation.

\section{REFERENCES}

Arulrajah, A., Piratheepan, J. \& Disfani, M. M. (2013). Reclaimed asphalt pavement and recycled concrete aggregate blends in pavement subbases: laboratory and field evaluation. Journal of Materials in Civil Engineering, 26, 349-357.

Avirneni, D., Peddinti, Pranav R. T. \& Saride, S. (2016). Durability and long-term performance of geopolymer stabilized reclaimed asphalt pavement base courses. Construction and Building Materials, 121, 198-209.

Chesner, W. H. \& Collins, R. J. (2019). FHWA research and technology, user guidelines for waste and byproduct materials in pavement construction (FHWA-RD-97-148).

Copeland, A. (2011). Reclaimed asphalt pavement in asphalt mixtures: State of the practice, Federal Highway Administration (FHWA-HRT-11-021).

Dachowskia, R. \& Kostrzewaa, P. (2016). The Use of Waste Materials in the Construction Industry. World Multidisciplinary Civil Engineering-Architecture-Urban Planning Symposium, 161, 754-758.

Davidovits, J. (2008). Geopolymer Chemistry and Applications. Second edition, Institute Geopolymer, Saint-Quentin, France.

Delwar, M., Fahmy, M. \& Taha, R. (1997). Use of reclaimed asphalt pavements as an aggregate in Portland cement concrete. ACI Materials Journal, 94(3), 251-256.

Environmental Protection Agency (EPA) (2019, June 30). Construction and demolition: Material-specific data. www.epa.gov/facts-and-figures-about-materials-waste-and-recycling/ construction-and-demolition-material-specific.

Environmental Protection Agency (EPA) (2019, June 30). Sustainable management of construction and demolition materials. www.epa.gov/smm/sustainable-management-construction-anddemolition-materials\#America.

Hajj, E., Sebaaly, P. \& Kandiah, P. (2010). Evaluation of the use of reclaimed asphalt pavement in airfield HMA pavements. J. Transp. Eng., 136, 181-189.

Hansen, Kent R. \& Copeland, A. (2014). Asphalt Pavement Industry Survey on Recycled Materials and Warm-Mix Asphalt Usage. National Asphalt Pavement Association (NAPA) IS 138(5e).

Hossiney, N., Wang, G., Tia, M. \& Bergin, M. J. (2010). Evaluation of Concrete Containing Rap for Use in Concrete Pavement. Pavement Res. Technol. 3(5):251-258

Horpibulsuk H., M. Hoy, Arulrajah, Arul (2016). Strength development of recycled asphalt pavement - Fly ash geopolymer as a road construction material. Construction and Building Materials, 117, 209-219.

Hoyos, L., Puppala, A. \& Ordonez, C. (2011). Characterization of cement-fiber-treated reclaimed asphalt pavement aggregates: preliminary investigation. Journal of Materials in Civil Engineering, 23, 977-989. 
Huang, B., Shu, X. \& Burdette, E. G. (2006). Mechanical Properties of Concrete Containing Recycled Asphalt Pavements. Magazine of Concrete Research.

Huang, B., Shu, X. \& Li, G. (2005). Laboratory investigation of Portland Cement Concrete Containing Recycled Asphalt Pavements. Cement and Concrete Research. 35(10):2008-2013

Kralj, D. \& Markic, M. (2008). Building materials reuse and recycle. Construction and Building materials, 4, 409 - 418.

Maher, M. H., Gucunski, N. \& Papp, W. (1997). Recycled Asphalt Pavement as a Base and SubBase Material, ASTM Special Technical Publication, 1275, 42-53.

Malhotra, V. M. (2010). Global warming and role of supplementary cementing materials and superplasticizers in reducing greenhouse gas emissions from the manufacturing of Portland cement. International Journal of Structural Engineering, 1, 116-130.

Morsy, M., Saleh, A., Al-Salloum, Y. \& Almusallam, T. (2014). Effect of sodium silicate to sodium hydroxide ratios on strength and microstructure of Fly ash geopolymer binder. Arabian Journal for Science and Engineering, 39(6), 4333-4339.

Natik, T. R. (2015). Sustainability of Cement and Concrete Industries. Achieving Sustainability in Construction. https://www.icevirtuallibrary.com/doi/10.1680/asic.34044.0017

Puppala, A. J., Saride, S. \& Williammee, R. (2011). Sustainable reuse of limestone quarry fines and RAP in pavement base/subbase layers. J. Mater. Civ. Eng., 24, 418-429.

Ramzi, T. G., Ali, A., Basma, O. \& Al-Turk (1999). Evaluation of reclaimed asphalt pavement aggregate in road bases and subbases. Transportation Research Record, 1652, 264-269.

Salloum, T. (2007). Effect of Fly ash Replacement on Alkali and Sulphate Resistance of Mortars (MS Thesis). Department of Building, Civil and Environmental Engineering, Concordia University Montreal, Quebec, Canada. 